\title{
A Study on Acupuncture Treatment to Meniere's disease
}

\author{
Tong-zheng Hong* \\ As-You-Wish Healthcare Institute, freelance, Taiwan
}

Submission: December 29, 2017; Published: August 28, 2018

*Corresponding author: Tong-zheng Hong, Tong-zheng Hong, As-You-Wish Healthcare Institute, Taiwan, Tel: 093-3086-399;

Email: ty8876@ms24.hinet.net

\section{Abstract}

Yin-Yang balance is absolutely the unique concept of traditional Chinese medicine that distinguishes TCM from the Western medicine. A disease indicates a loss of the balance of Yin-Yang. The research shows acupuncture combined with western medicine comprehensive treatment (WMCT) can be more effective for the symptoms of Meniere's disease such as vertigo and dizziness, but it still remains uncertain whether or not acupuncture is good for hearing loss.

Keywords: Meniere’s disease, Dampness; Acupuncture Treatment; WHO; Patients vertigo; Hearing threshold; Blood

Abbreviations: APS: Acupuncture Point Stimulation; WMCT: Western Medicine comprehensive Treatment; TCM: Traditional Chinese Medicine; NIDCD: National Institute on Deafness and Other Communication Disorders

\section{Introduction}

In general, most people in Taiwan present themselves to the medical doctors first when they are in need of medical treatments. Part of this fact is because there are not sufficient scientific researches to prove the effects of the traditional Chinese medicine (TCM), acupuncture, or acupressure. Compared to the current acupuncture developments in Taiwan, acupuncture has gained more and more popularity in the past 40 years and been considered "essential health benefits" and has been more commonly used for pain conditions than general medical problems or addiction management in the US [1].

It is reported that The National Institute on Deafness and Other Communication Disorders (NIDCD) estimates that approximately 615,000 individuals are currently diagnosed with Meniere's disease and that 45,500 cases are newly diagnosed in the United States each year [2]. The present research shows Meniere's disease can develop at any age, but it is more likely to happen to adults between 40 and 60 years of age.

In the perspective of Western Medicine, Meniere's disease, which is anidiopathic inner ear disorder and usually affects only one ear, is defined as a disorder of the inner ear that can cause primary signs and symptoms like spontaneous episodes of vertigo along with fluctuating hearing loss, ringing in the ears (tinnitus), hearing loss, and a feeling of fullness or congestion in the ear.

Attacks of dizziness may occur suddenly or after a short period of tinnitus or muffled hearing. Some of the patients may have single attacks of dizziness separated by long periods of time, but others may experience many attacks closer together over a few days. Some people with Meniere's disease are reported to have vertigo so extreme that they can lose their balance and fall. Unfortunately, there are no definite answers are available to explain what happens to cause Meniere's disease based on the existing theories [2].

Possible causes may include improper fluid drainage, abnormal immune response, allergies, viral infection, genetic predisposition, head trauma, and migraines. The commonly administered therapies are noninvasive therapies, such as rehabilitation, hearing aid, Meniett device, middle ear injections, and surgery [3].

\section{Materials and Methods}

\section{Search strategy}

The combinations of the terms "acupuncture and Meniere's disease" were used for searching on PubMed.

\section{Selection criteria}

English articles were eligible for inclusion. Each research identified in the search was evaluated for the tools. Acupuncture used in combination with medicines, moxibustion, Chinese herbs, and cupping were excluded.

\section{Result}

A total of 3 articles were identified in the literature search. Among these articles, the definite conclusions are presented that acupuncture can be conducted with potential benefits for the 
person with Meniere's disease [4-6], as shown in Table 1. These promising results indicate that acupuncture cannot only be used for pain management but also for Meniere's disease.

Table 1: Outcomes of acupuncture for Meniere's disease.

\begin{tabular}{|c|c|c|c|}
\hline Author(s) & $\begin{array}{c}\text { TCM } \\
\text { Pattern }\end{array}$ & $\begin{array}{c}\text { Side } \\
\text { effects }\end{array}$ & Outcomes \\
\hline He JJ, et al. [4] & - & - & $\begin{array}{c}\text { The acupuncture point } \\
\text { stimulation (APS) might be a } \\
\text { promising therapeutic approach } \\
\text { for Meniere's disease (MD). }\end{array}$ \\
\hline $\begin{array}{c}\text { Long AF, et } \\
\text { al. [5] }\end{array}$ & - & - & $\begin{array}{c}\text { The weight of evidence, across } \\
\text { all study types, is of beneficial } \\
\text { effect from acupuncture for } \\
\text { those in an acute phase or } \\
\text { those who have had Meniere's } \\
\text { syndrome for a number of years. }\end{array}$ \\
\hline $\begin{array}{c}\text { Steinberger } \\
\text { A, et al. [6] }\end{array}$ & - & - & $\begin{array}{c}\text { After acupuncture treatment } \\
\text { the patients' conditions greatly } \\
\text { improved. In most cases } \\
\text { hearing level had not greatly } \\
\text { varied, so the other symptoms } \\
\text { of Meniere's disease were not } \\
\text { present in any large degree. }\end{array}$ \\
\hline
\end{tabular}

In the report by $\mathrm{He}$, et al. [4], efficacy standard made by Chinese Medical Association of Otorhinolaryngology, which contained the assessment of vertigo of frequency and hearing was adopted. The result of the meta-analysis for the vertigo showed a fixed effects model in which should be used because the acupuncture point stimulation (APS) combined with western medicine comprehensive treatment (WMCT) had a better effect than WMCT alone. The data did not show significant difference between APS plus WMCT and WMCT alone in the improvement of hearing; however, the hearing did not get worse, indicating APS is not hopeless to treating hearing loss [4].

Particular symptoms of dizziness and vertigo were often mentioned as part of the achieved outcomes presented in the research by Long et al. [5]. They also suggested that it is important for all acupuncturists in the UK or Europe to adopt a TCM diagnosis and treatment approach.

Steinberger and Pansini stated in their research that the classic symptoms of Meniere's disease are vertigo, tinnitus and deafness, and among all the treated patients vertigo was the most uncomfortable and distressing symptom. In all of their cases vertigo stopped after a few acupuncture courses. However, they suggest it is more important to follow and control hearing threshold because the other symptoms of Meniere's disease also do not persist as long as the hearing threshold remains stable [6].

\section{Discussion}

Meniere's disease is one of the illnesses the WHO recommended in 1979 to treat with acupuncture.

Yin-Yang balance is the unique concept and one of the key principles of traditional Chinese medicine. Diseases are understood as a loss of balance between Yin and Yang as shown in Figure 1. Yin-Yang balance has been described throughout the history of Chinese medicine for many centuries and still serves as the foundation and the guide for the explanation of etiology of diseases [7].

\begin{tabular}{cc} 
Yin & Yang \\
\hline & \\
Blood & Qi \\
Material & Function \\
Zang & Fu \\
Yin meridian & Yang meridian
\end{tabular}

Figure 1: Characteristics of Yin and Yang

Signs and symptoms in Traditional Chinese medicine are broader than those in Western medicine. In general TCM physicians usually do not follow typical Western pathological classifications of diseases, but rather rely on the patterns individualized by the imbalance of Yin and Yang, Qi, and Blood, and body fluids in the body. In other words, the loss of balance between Yin and Yang results in diseases. Blood (Xue) and Qi can be classified into Yin and Yang based on the TCM theory. Blood is classified into Yin and derived mainly from gu qi (food qi) that is produced by the Spleen. One of the functions of Blood is considered to be the nourishing agent. The other source that generates Blood is Kidney storing Jing (essence) that can produce marrow. Marrow then generates bone marrow contributing to manufacturing Blood. On the other hand, oxygen is equivalent to Qi to some extent. Qi, which is categorized as Yang, is viewed as a type of life-giving energy circulating throughout the body in special meridians [1]. The concepts of "Qi is the commander of Blood and Blood is the mother of Qi" highlight Qi interacts with Blood to maintain the functions of Zang-Fu organs and has been used as the guide to treat the issues of Blood and Qi [8].

In the volume of Su Wen (Essential Questions) of Huang Di Nei Jing (Essential Questions of Yellow Emperor's Inner Classic), it is stated that "three Yang meridians of women is weaken at 42 , and Kidney qi of men is deficient at 40 ", which may be the invaluable guidelines to explaining why Meniere's disease is more likely to happen to adults between 40 and 60 years of age. The key to this thought lies in Kidney that plays an important role in understanding the relationship between aging and Meniere's disease.

The Zang-Fu theory, the Five Elements theory and patterns are unique and absolutely different from those theories of the Western medicine. In general, those who have not learned TCM are usually confused with the functions of internal organs (Zang$\mathrm{Fu}$ ) in the TCM. Kidney in the TCM is referred to as the "Root of Life" because it stores Essence (Jing). Essence is the creator of life and the foundation for Yin and Yang. On the other hand, the essence the Kidney stores is the foundation of producing Marrow, which is often misunderstood because it cannot exactly correspond to bone marrow in the Western medicine. Essence 
can be transformed into Blood, and Blood nourishes Essence. In other words, both Blood and Essence interact with each other to maintain the Yin level for normal functions in the body [9].

In the perspective of traditional Chinese medicine, abnormal fluid is defined as Dampness, which can damage the Yang of the body to stagnate fluids causing Qi stagnation Blood stasis. On the other hand, this evil is heavy, tenacious, can last for a long time and become difficult to treat, and tends to move downwards in the body. Dampness arising from Spleen qi deficiency often compromises immunity due to congestion of lymphatic system and autoimmune conditions to cause symptoms such as bloating, nausea, vomiting, heaviness of head and body, low appetite, and dizziness [7]. It is indicated that Liver and Kidney share the same origin. When Kidney functions normally, the Liver qi is able to ensure Qi to circulate consistently and smoothly in all parts of the body and not to invade Spleen.

Zangs mainly related to the etiology of Dampness include Lung, Spleen, and Kidney. Table 2 presents the differences between the functions of the Zangs in the Western medicine and the Traditional Chinese Medicine.

Table 2: Dampness-related Zangs.

\begin{tabular}{|c|c|c|}
\hline Lung & Western Medicine & $\begin{array}{c}\text { Traditional } \\
\text { Chinese Medicine }\end{array}$ \\
\hline Spleen & $\begin{array}{c}\text { Production of opsonins, } \\
\text { properdin, and tufts in } \\
\text { Creation of red blood cells. } \\
\text { Storages of red blood cells, } \\
\text { lymphocyte and other formed } \\
\text { elements }\end{array}$ & $\begin{array}{c}\text { Control Blood } \\
\text { Control and create } \\
\text { Qi }\end{array}$ \\
\hline Kidney & Excretion of urine & $\begin{array}{c}\text { Stores essence } \\
\text { (Yin) } \\
\text { Governs water } \\
\text { Controls the } \\
\text { reception of Qi }\end{array}$ \\
\hline
\end{tabular}

The most critical notion that "Feng (Wind), the beginner of the illness" is presented in Huang Di Nei Jing (Essential Questions of Yellow Emperor's Inner Classic). In addition to Dampness, this notion pinpoints that Wind, which may be associated with vertigo and dizziness in the patients with Meniere's disease, should be considered to be the major cause of ilness with its pernicious influence and indicates that Blood mobilization and Qi regulation need to be considered simultaneously for the better results [10]. It is also stated that Blood Xu (deficiency of Blood) resulted from Blood stasis and impeded Qi generates Wind. Pain, tremor, dizziness, and spasm are the representations of Wind. Yeo et al. [11] reported that behavioral tests showed that acupuncture stimulations at GB34 and LV3 could improve the motor dysfunction like tremors and dizziness that are the representations of Wind resulted from Blood deficiency.

Meniere's disease usually affects only one ear leading to hearing difficulty or loss, which currently cannot be solved with special medical remedy well. In Huang and Li's observation and clinical experience, it is stated APS could have good effect in controlling the vertigo and dizziness but it was not good in improving the hearing issue [12].

Fluid drainage may be the cause of the tinnitus, which is an easily negligible and terrible symptom to impact the patients' quality of life [13]. This issue seldom draws any attentions in the present studies. Whether or not the application of acupuncture can be effect for the tinnitus has been in debate for over 40 years and has not reached a definitive conclusion [14]. In clinical literature, GV20 (Baihui) was used for the treatment of the symptoms of Meniere's disease, including tinnitus [15].

Unfortunately, the literature reviews of this study show that patterns which play the key roles in the TCM for diagnosis and treatment were not included, and the side effects were not discussed in the previous studies.

\section{Conclusion}

Patients and health providers may take clinical effectiveness, cost effectiveness, and side effects into consideration in deciding modalities. Even though acupuncture may be insufficient to treat hearing issue, acupuncture may be more feasible for Meniere's disease than the Western medicine with respect to time and convenience.

\section{Referencers}

1. Hong TZ (2017) Exploring a New Extra Point for Sub-acute Cough: A Case Report. Scholar's Press, Germany.

2. National Institute on Deafness and Other Communication Disorders (NIDCD). Meniere's disease.

3. Mayo Clinic. Meniere's disease.

4. He JJ, Jiang LY, Peng TQ, Xia MX, Chen H (2016) Acupuncture Points Stimulation for Meniere's Disease/Syndrome: A Promising Therapeutic Approach. Evid Based Complement Alternat Med 2016: 6404197.

5. Long AF, Xing M, Morgan K, Brettle A (2011) Exploring the Evidence Base for Acupuncture in the Treatment of Ménière's Syndrome-A Systematic Review. Evid Based Complement Alternat Med 2011: 429102.

6. Steinberger A, Pansini M (1983) The treatment of Meniere's disease by acupuncture. Am J Chin Med 11(1-4): 102-105.

7. Maciocia G (1989) The foundations of Chinese Medicine. Library of Congress Cataloging in Publication Data. NY.

8. Hong TZ (2017) Exploring a New Extra Point for Subacute Cough: A Case Report. J Complement Med Alt Healthcare 3(4): 555619.

9. Hong TZ (2017) Acupressure or Acupuncture at Sanyinjiao (SP6) for Primary Dysmenorrhea. J Network Med Target Ther 1(1).

10. Sun P (2010) Treatment of Pain with Chinese Herbs and Acupuncture. 2011. Churchill Livingstone, NY.

11. Yeo S, Choi YG, Hong YM, Lim S (2013) Neuroprotective Changes of Thalamic Degeneration-Related Gene Expression by Acupuncture in an MPTP Mouse Model of Parkinsonism: Microarray Analysis. Gene 515(2): 329-338.

12. Huang N, Li C (2012) Recurrent sudden sensorineural hearing loss in a 58-year-old woman with severe dizziness: a case report. Acupunct Med 30(1): 56-59. 
13. Stephens D, Pyykko I, Yoshida T, et al. (2012) The consequences of tinnitus in long-standing Ménière's disease. Auris Nasus Larynx 39(5): 469-474.

14. Tassinari M, Mandrioli D, Gaggioli N, Roberti Di Sarsina P (2015) Ménière's disease treatment: a patient-centered systematic review. Audiology and Neurotology 20(3): 153-165.

This work is licensed under Creative Commons Attribution 4.0 License DOI: 10.19080/JCMAH.2018.07.555715
15. Huang Y, Chen JQ (2007) Professor OUYANG Qun's clinical experience on application of single point. Zhongguo Zhen Jiu 27(11): 857-858.

\section{Your next submission with Juniper Publishers} will reach you the below assets

- Quality Editorial service

- Swift Peer Review

- Reprints availability

- E-prints Service

- Manuscript Podcast for convenient understanding

- Global attainment for your research

- Manuscript accessibility in different formats (Pdf, E-pub, Full Text, Audio)

- Unceasing customer service

Track the below URL for one-step submission https://juniperpublishers.com/online-submission.php 